\title{
The Application of Information Systems of FreestyleXtreme
}

\author{
N P SINGH \\ Management Development Institute, Gurgaon \\ Mehrauli Road, Sukhrali, \\ Gurugram-122007, India \\ Email: knpsingh@mdi.ac.in; netra.singh@gamil.com
}

\section{About the author}

Dr. Netra Pal Singh has been a professor of Information Systems at Management Development Institute (MDI) in India since 2002. He received his M.Sc. from CCS Meerut University Meerut, M.S. from Birla Institute of Technology \& Science, and Ph.D. from CCS Haryana Agriculture University (HAU) in India. He is recipient of Young Scientist Award from Indian Society of Agricultural Statistics. His research experience and interests are applications of artificial intelligence, telecommunication management, business intelligence, enterprise systems and optimization models.

\section{Abstract}

In recent years, retailers across the globe are using information systems/information technology to do their day to day, end-to-end transactions and implementing these technologies to serve their purpose better. Retailers are also very quick to replace their legacy systems to new ones with better features to meet their emerging needs. FreestyleXtreme is no exception to these trends. Information Systems are at the core of FreestyleXtreme strategy to survive, grow (volume \& geography) and serve the customers with higher satisfaction. This paper is an attempt to study the role and growth of the information systems at FreestyleXtreme and find out how these information systems helped the company to achieve its goals with a specific reference to the application of artificial intelligence. The paper presents all facets of implementation of the information systems, including social media and benefits accruing to FreestyleXtreme.

Keywords: Brand and Website, Customer Experience, Transparent Communications, Information Systems, Artificial Intelligence 


\section{Introduction}

The idea of FreestyleXtreme was conceived by Jeff Loughlin and Ben Richardson at one of their meetings in 2003. During the same time, they used to travel around Europe in a beat-up old truck, to MotoGP, MXGP, Supercross, Superbike, festivals and other events that allow them to sell their sports products. After attaining the experience of working with a mobile store, FreestyleXtreme decided to establish its website in 2004. The website was launched in eight languages and five currencies were allowed to use for payment. It was a unique feature in 2004. In 2006, the company built a small warehouse and shifted there from their garden store. In the meanwhile, the company became a license holder for well-known US brands, having a mail-order catalog, a mobile store, a Freestyle Motocross (FMX) team, and also a design studio. During the same period, FreestyleXtreme borrowed money from the market and moved to its official office first time in Bristol, UK.

In 2008, in the face of the global financial crisis, the company shut down all of its business ventures, except for the website. By the year 2010, the company gained its size again with a full focus on business based on its website (FreestyleXtreme.com). During 2010-11, the company became a global retailer, regularly shipping to $60+$ countries around the world each month through 20 multilingual, multi-currency websites. The company stocked most of the biggest brands in action sports. Its warehouse size grew from a 1,500 square foot warehouse to a 15,000 square foot modern facility.

As per the company website, 2012 was an excellent year for it. After a successful launch into the mountain bike market, the company received several awards. These awards were featured by the biggest computer games franchises in the world. As a result of its success, FreestyleXtreme was invited to speak to the prime minister of the United Kingdom in 2013. In the same year, the company received the highest customer feedback (9.8 stars out of 10$)$ on its website review.

In 2014, the company launched its own magazine when print media was dying out in the action sports industry. It also created a snowboarding department. After two years, the company entered the skate market through its collaboration with the local skate parks. This has brought about further sales growth of its skateboarding products and the new venture became another success story for the whole company.

In 2017, the company redesigned its logo so that it represents the company's business activities better. A year later, in 2018, the company was reported by The Sunday Times in its prestigious Fast Track 100 and ranked as one of Britain's 100 fastest-growing companies. In 2018, the company entered into three new sports markets, i.e., Cycle, Surf and Motorcycle. Though FreestyleXtreme did not have a big plan for its

future expansion, it has been growing continuously and investing in new and old markets. Evidence is shown in its growth and success in the past that it will continue to compete with bigger businesses in size.

The total amount of the company's international sales was $£ 8560,000$ and the total sales was $£ 10,771,000$ in 2017. The company recorded a growth rate of $41.56 \%$ in international sales during 2017 2018. The company has more than 100,000 products including streetwear, footwear, motocross gear, mountain bike gear, snowboarding equipment, skate shoes, skateboards, bags and accessories. 
As evident from the data given above, the company continued to maintain its multilingual website and abandon other plans during the financial meltdown. This implies that company highly depends on technology which makes it in line with other successful e-commerce companies. The company has upgraded its technology to realize more efficient operation by cutting costs and continuing its customer-centric strategy.

This study is an attempt to analyze the impact of information systems (such as website creation where artificial intelligence technologies are firmly embedded) on the performance of the FreestyleXtreme in terms of customer satisfaction, operational efficiencies, increase in profits and reduction in the costs. The data used in this study are drawn and compiled from different sources on FreestyleXtreme. The research methodology used in this article can be termed as exploratory and descriptive. It is based on qualitative study as well as quantitative data collected from different sources online. The data can be divided into two types. The first one is related to the implementation and usage of information systems within FreestyleXtreme. The second type is related to the roles of the information systems within the ecosystem of FreestyleXtreme. These roles are (i) automate, (ii) informate and (iii) transformate as outlined by Schein (1992) and Zuboff (1988).

As explain above, this study has three objectives:

(i) To examine the present status of information systems/ technologies adopted or implemented by FreestyleXtreme;

(ii) To investigate the impact of information systems/ technologies on the performance of FreestyleXtreme.

(iii) To identify the internal and external factors influencing the adoption of information systems/technologies by FreestyleXtreme.

\section{Financial and Growth Statistics}

As mentioned above, the company started its business in 2003 in United Kingdom and is providing service in $60+$ countries presently, using a website which runs in 20 languages. The data of the performance of the company for the selected years is presented in this section, including parameters such as sales revenue, assets \& liabilities, key financial ratios, manpower, number of orders handled per day, SKUs and warehouse.

\section{Sales Revenue}

This section compiles the data of the company's sales revenue in Tablem. It is evident that the sales revenue has grown about four times in 2018 in comparison to the year 2010. This shows the significant growth of the company in the recent decade.

\section{Assets \& Liabilities}

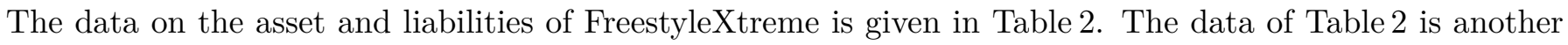
proof of the company's rapid expansion. Its total assets have increased from $£ 597,455$ in 2010 to $£ 3,188,119$ in 2017 , but the data with respect to its net assets does not support a better prospect. 
Table 1 Performance Indicators

\begin{tabular}{|l|l|l|l|l|l|}
\hline Year & Transactions & Products Sold & $\begin{array}{l}\text { Average Or- } \\
\text { der Value }\end{array}$ & International sales & Sales Revenue \\
\hline 2010 & 37,744 & 81,079 & $€ 69.09$ & NA & $€ 2,607,576.36$ \\
\hline 2011 & 54,697 & 107,937 & $€ 71.27$ & NA & $€ 3,898,076.68$ \\
\hline 2018 & NA & NA & NA & $£ 8,560,000.00$ & $£ 10,771,000.00$ \\
\hline
\end{tabular}

Sources: [1]: The Marketing Society (2013).

[2]: http://www.fasttrack.co.uk/company_profile/FreestyleXtreme/

Table 2 Asset and Liabilities

\begin{tabular}{|l|l|l|l|l|l|l|}
\hline Year & $\begin{array}{l}\text { Total Asset } \\
(£)\end{array}$ & $\begin{array}{l}\text { Total Liabili- } \\
\text { ties }(£)\end{array}$ & $\begin{array}{l}\text { Net Assets } \\
(£)\end{array}$ & $\begin{array}{l}\text { EBADTA } \\
(£)\end{array}$ & $\begin{array}{l}\text { Cash in } \\
\text { Bank }(£ K)\end{array}$ & $\begin{array}{l}\text { Debt Ratio } \\
(\%)\end{array}$ \\
\hline 2010 & 597,455 & 595,977 & $+1,478$ & - & 13,560 & NA \\
\hline 2011 & 387,621 & 391,508 & $-3,887$ & 23,900 & 9,431 & NA \\
\hline 2012 & $1,541,055$ & $1,637,035$ & $-95,980$ & 61,268 & 2,461 & NA \\
\hline 2013 & $2,251,547$ & $2,598,638$ & $-347,091$ & 85,737 & 11,051 & NA \\
\hline 2014 & $2,997,210$ & $3,208,558$ & $-211,348$ & 101,914 & 20,652 & NA \\
\hline 2015 & $2,847,527$ & $3,408,596$ & $-561,069$ & 106,076 & 17,463 & NA \\
\hline 2016 & $2,873,723$ & $3,564,863$ & $-691,140$ & 112,232 & 12,882 & NA \\
\hline 2017 & $3,188,119$ & $4,058,767$ & $-870,648$ & - & 50,619 & 127.31 \\
\hline
\end{tabular}

Sources:

https://data.be/en/company/FreestyleXtreme-Trading-Ltd-ENT-E-0568452761\#0verview https://suite.endole.co.uk/insight/company/06950212-FreestyleXtreme-trading-limited https://uk.globaldatabase.com/company/FreestyleXtreme-trading-limited\#div_financials

\section{Key Ratios and Manpower}

Only 85 staff were deployed to FreeStyleXtreme at the end of 2018. The company might downsize its manpower in the wake of the uncertainty with respect to Brexit. It is reported that FeeStyleXtreme lost 15 jobs in UK because the opening of its office in Europe and recruitment and investments are in hold (Baker, 2018). The key financial ratios of the company along with the source are given in Table[3. However, these ratios did not indicate good financial health of the company.

\section{SKUs (Stock Keeping Units) \& Warehouse}

The company's warehouse size has grown to 15,000 square feet in Bristol from 1,500 square feet. It stocks around 30,000 SKUs and 100,000 items, and typically handles 800 orders per day, a figure which can be more 
Table 3 Key Financial Ratios

\begin{tabular}{|c|c|c|c|c|c|}
\hline Ratios & $\begin{array}{l}\text { July } 31, \\
2012 \quad \sim \text { July } \\
31,2013\end{array}$ & $\begin{array}{l}\text { July } \begin{array}{r}31, \\
2013 \sim \text { July } \\
31,2014\end{array}\end{array}$ & $\begin{array}{l}\text { July } 31 \text {, } \\
2014 \sim \text { July } \\
31,2015\end{array}$ & $\begin{array}{lr}\text { July } & 31, \\
2015 \quad \sim \text { July } \\
31,2016\end{array}$ & $\begin{array}{l}\text { July } \begin{array}{r}31, \\
2016 \quad \sim J u l y \\
31,2017\end{array}\end{array}$ \\
\hline Current Ratio & 0.86 & 0.97 & 0.76 & 0.63 & 0.6 \\
\hline Gearing Ratio & -351.53 & -584.76 & -192.49 & -118.84 & -78.31 \\
\hline Equity & -28.66 & -10.91 & -31.43 & -38.57 & -40.7 \\
\hline Liquidity & 0.30 & 0.26 & 0.20 & 0.18 & 0.16 \\
\hline Current Debt Ratio & -3.97 & -9.33 & -4.15 & -3.97 & -3.9 \\
\hline Total Debt Ratio & -7.49 & -15.18 & -6.08 & -5.16 & -4.66 \\
\hline Manpower & NA & NA & NA & 50 & 63 \\
\hline
\end{tabular}

Source:

https://suite.endole.co.uk/insight/company/06950212-freestylextreme-trading-limited?page= financials

than double in the run up to Christmas peak (Tran, 2017). It plans to open another warehouse in Germany in view of Brexit and has already opened its office in Romania (Baker, 2018).

\section{Business Strategies and Delivery Business Model}

The core of the business strategies of FreeStyleXtreme is centricity of customer satisfaction or customer experience. The advantage of its business model is reflected through delivery (Dawson, 2018). The basic rule of its business strategy is high performance. Dawson (2018) reported that FreeStyleXtreme used Royal Mail's international delivery services in its early years of operations. Because it was not possible for customers to track their orders with Royal Mail, the company replaced this delivery system into WnDirect WnDirect offers fully customizable solutions to users, flexibility in order fulfilment and together with transparency with respect to the status of the delivery from its start to the end. This presents better in line with the customer centric strategy of FreeStyleXtreme. The initiatives of these business strategies and the delivery model are briefed in the following.

\section{Customer-Centric Strategy}

As part of the business strategy, FreeStyleXtreme has taken many initiatives to improve its performance in the recent years. The keyword in all initiatives is the customer centricity. Selected initiatives of the customer centric strategy include (1) Operations and communications and (2) B2C Europe's Solution. 


\section{Operations and Communications}

Franklin (2017) confirmed that the business strategy of FreeStyleXtreme with respect to its operations is built around customer experience. The company always keeps customers at every point of the loop. By showing the status of the orders only, the burden on the call center of the company has been largely reduced, and the reputation of the brand has been improved. FreeStyleXtreme makes efforts to follow the standard operation procedures to reduce ambiguity, enhance the proper form of its organization structure and make use of the reviews on social media as an integral part of its customer centric strategy. It is worth mentioning that the heads of the various functional units (such as logistics, refunding etc.) are directly communicating with customers. Feedbacks are requested about the performance of the FreeStyleXtreme team from the customers within 7 to 14 days of the receipt of the parcel. Negative feedbacks are taken up seriously by the company to improve the operation process and communications among its team. Employees are empowered to make a difference based on the feedbacks and are authorized to make necessary changes to deliver higher customer satisfaction.

\section{B2C (Business to Customer) Europe's Solution:}

FreeStyleXtreme has implemented its B2C Europe's solution to meet the requirement of e-commerce platforms (such as Amazon) which require a local return address for the purchasing customers. The B2C Europe's solution has saved thousands of ponds for FreeStyleXtreme and increased its business to the local customers (B2C Europe, 2019).

\section{Delivery Business Models of FreeStyleXtreme}

It is evident form the data given in Table田 and Table 1 that the company's delivery discounting model aims to increase the value of each order and the margins for each order in turn. Another feature of this model is the number of days it takes to deliver an order to the customer premises. Cost is the direct functional factor which integrates distance and number of delivery days. However, in many cases, a favourable destination is decisive for the calculation of the total delivery cost.

There are three important components of the FreeStyleXtreme's delivery business model. These are free shipping policy for a given amount of orders to a specific country, assessment of custom fee for non-UK

Table 4 Delivery Business Model for UK

\begin{tabular}{|l|l|l|l|}
\hline Delivery Options & Charges & Working Days & Discounts \\
\hline Standard Tracked Delivery & $£ 1.99$ & $3-4$ Working Days & Free for orders over $£ 49.99$ \\
\hline Next Working Day Delivery & $£ 5.99$ & $1-1$ Working Days & $£ 3.99$ for orders over $£ 49.99$ \\
\hline Saturday Delivery & $£ 5.99$ & $1-7$ Working days & $£ 3.99$ for orders over $£ 49.99$ \\
\hline
\end{tabular}

Source: Website of FreeStyleXtreme 
The Application of Information Systems of FreestyleXtreme

Table 5 Delivery Business Model for Selected Countries

\begin{tabular}{|l|l|l|l|}
\hline Country/ Delivery Options & Charges & Working Days & Discounts \\
\hline Standard Tracked Delivery & $\$ 24.95$ & $7-9$ & Free for orders over $\$ 199.95+$ \\
\hline Superfast Delivery & $\$ 49.95$ & $3-4$ & $£ 34.95$ for orders over $\$ 199.95+$ \\
\hline Standard Tracked Delivery & $\$ 14.95$ & $6-11$ & Free for orders over $\$ 129.95+$ \\
\hline Standard Tracked Delivery & $\$ 29.95$ & $5-8$ & Free for orders $\$ 199.95+$ \\
\hline Standard Tracked Delivery & $€ 5.95$ & $4-6$ & Free for orders $€ 99.95+$ \\
\hline Express Delivery & $€ 12.95$ & $2-3$ & $€ 5.95$ for orders $€ 99.95+$ \\
\hline Standard Tracked Delivery & $\$ 14.95$ & $7-9$ & Free for orders $\$ 99.95+$ \\
\hline Superfast Delivery & $\$ 24.95$ & $2-3$ & $\$ 19.95$ for orders $\$ 99.95+$ \\
\hline Standard Tracked Delivery & $€ 6.95$ & $5-7$ & Free for orders $\$ 99.95+$ \\
\hline Express Delivery & $€ 15.95$ & $3-4$ & $€ 11.95$ for orders $\$ 99.95+$ \\
\hline Superfast Delivery & $€ 24.95$ & $1-2$ & $€ 14.95$ for orders $\$ 99.95+$ \\
\hline Standard Tracked Delivery & PLN 29 & $5-7$ & Free for orders over PLN $349+$ \\
\hline Express Delivery & PLN 49 & $4-5$ & PLN 29 for orders of PLN $349+$ \\
\hline Superfast Delivery & PLN99 & $1-2$ & PLN 79 for orders of PLN $349+$ \\
\hline Standard Tracked Delivery & $€ 5.95$ & $3-6$ & Free for orders $€ 79.95+$ \\
\hline Express Delivery & $€ 10.95$ & $2-3$ & $€ 6.95$ for orders $\$ 79.95+$ \\
\hline Superfast Delivery & $€ 16.95$ & $1-2$ & $€ 12.95$ for orders $\$ 79.95+$ \\
\hline Standard Tracked Delivery & $€ 4.95$ & $5-7$ & Free for orders $€ 99.95+$ \\
\hline Express Delivery & $€ 14.95$ & $3-4$ & None \\
\hline Superfast Delivery & $€ 24.95$ & $1-2$ & $€ 14.95$ for orders $\$ 99.95+$ \\
\hline Soure: Webite 5 & & \\
\hline
\end{tabular}

Source: Website of FreeStyleXtreme

orders and effective return policy (time limit is within 45 days of the shipping date and customer may opt for either a refund or exchange). In summary, delivery business model not only puts an emphasis on the total value of orders, but also take sufficient account of the cost of the items, shipping charges, custom fees, coupon discounts as applicable and shipping charges.

\section{Status and Impact of Information Technology (IT)/ Information}

\section{Systems (IS)}

The company was set up in 2003, and the process of automation began in 2009 as mentioned in the previous section. For several years at the early stage, the company invested in IT systems and each investment resulted in both tangible and intangible benefits as per the data reported. The major information systems implemented finally include (i) Websites of the company; (ii) Machine learning algorithm based marketing 
Table 6 IT Systems and Technology Providers

\begin{tabular}{|c|c|c|c|c|c|}
\hline $\begin{array}{l}\text { IT Sys- } \\
\text { tem }\end{array}$ & Category & Major Role & Vendor & $\begin{array}{l}\text { Adoption } \\
\text { Year }\end{array}$ & Source \\
\hline $\begin{array}{l}\text { E-Com } \\
\text { website }\end{array}$ & Website & $\begin{array}{l}\text { Online mar- } \\
\text { keting }\end{array}$ & Not Mentioned & 2004 & Marotta (2013) \\
\hline- do & Website & $\begin{array}{l}\text { Online Mar- } \\
\text { keting }\end{array}$ & $\begin{array}{l}\text { Not Mentioned (For } \\
\text { Australia) }\end{array}$ & 2012 & $\begin{array}{l}\text { Website of the } \\
\text { Company }\end{array}$ \\
\hline AD Mgt. & Ad Software & Advertisement & Marin Software & $\begin{array}{l}\text { Not } \\
\text { Given }\end{array}$ & $\begin{array}{l}\text { Marin } \quad \text { Software } \\
(2019)\end{array}$ \\
\hline $\mathrm{CM}$ & $\begin{array}{l}\text { Carrier Man- } \\
\text { agement }\end{array}$ & $\begin{array}{l}\text { Online Fulfil- } \\
\text { ment \& }\end{array}$ & $\begin{array}{l}\text { Returns Route Genie } \\
\text { software from iForce } \\
\text { (SaaS Model). }\end{array}$ & 2016 & $\begin{array}{l}\text { LogisticManager.com } \\
(2016), \quad \text { News } \\
(2018)\end{array}$ \\
\hline $\begin{array}{l}\text { Cloud- } \\
\text { based } \\
\text { WMS }\end{array}$ & $\begin{array}{l}\text { Warehouse } \\
\text { management } \\
\text { System }\end{array}$ & $\begin{array}{l}\text { Warehouse } \\
\text { Management }\end{array}$ & $\begin{array}{l}\text { Snapfulfil } \\
\text { (www.snapfulfil.com/) }\end{array}$ & 2017 & Strzalek (2018) \\
\hline $\begin{array}{l}\text { AI Based } \\
\text { Market- } \\
\text { ing }\end{array}$ & $\begin{array}{l}\text { Campaign } \\
\text { Management }\end{array}$ & $\begin{array}{l}\text { E-mail cam- } \\
\text { paign }\end{array}$ & Emarsys & 2017 & Reed (2017) \\
\hline
\end{tabular}

applications (Administrator, 2018); (iii) Marin Software, a cross-channel performance advertising platform consisting of patented bidding algorithm; (iv) Carrier management, Route Genie software from iForce (SaaS Model).; (v) Cloud-based warehouse management system from Snapfulfil (https://www.snapfulfil.com/); (vi) Order processing system; (vii) Stock control system; (viii) ERP \& CRM systems integrated with the e-commerce website. These technological interventions are summarized in described briefly as in Table $\mathbf{1}$ and the subsequent sections.

\section{Website}

The website of FreeStyleXtreme is developed using ASP.Net framework. As on Nov. 3, 2018, 49 technologies were detected on this page and 57 technologies were removed from the website. On Oct. 28, 2018, as per Alexa Traffic Statistics, FreeStyleXtreme website ranked 83,360 globally and the UK rank was 9,731. The participants of the survey included $22.1 \%$ from UK, $12.9 \%$ from US, $7.8 \%$ from Poland, $7.6 \%$ from Spain, $7.2 \%$ from France and $42.4 \%$ from other countries. The bounce rate of the website was $42.7 \%$, daily page views per visitor were 6.7 , and the daily time spent on the website was 3.56 minutes. $40.1 \%$ of its web traffic came via search engines. Its upstream websites are google.com (18.3\%), google.co.uk (4.7\%), Facebook (2.4\%), Google.pl (2.1\%), YouTube.com (1.9\%), and others.

\section{Emarsys Al Platform at FreeStyleXtreme}

The company is sending 20 different mails to the same segment of customers since customers are interested in large number of sports products (Reed, 2017). Obviously, the small number of employees cannot do 
it with traditional technology support. Emarsys offers a potential solution to the issue in its AI-enabled cloud marketing platform, which includes automation, smart insight, web extend, predict (web and email) and smart content components (Reed, 2017; Briggs, 2017). This AI platform is mainly based on machine learning algorithms and data science. FreeStyleXtreme implemented this software by providing a link from its customer database into the platform, which combines online behaviour with product interest and purchasing history to generate recommendations for customers through campaign emails. Such instant information is also available to online purchasers doing purchase at the meantime. Tjepkema (2017) mentioned that Emarsys Smart Content takes just two hours to send tailored emails to half a million international customers across 60 markets in 14 languages. It relieves the manpower of the company from creating effective contents of emails repeatedly.

\section{Why FreeStyleXtreme Implemented Al platform?}

As per Media Release (2017), the company implemented AI-based cloud platform from Emarsys to support its international expansion plan, increase revenue, engage with the personalized needs of the customers, increase agility, and save times for its employees. The company believes that the AI platform is not a hype but a reality to do business in a most efficient manner (Croud, 2018; Everett, 2017).

\section{Impact/ Benefits of Al Platform}

The following impacts and benefits have been highly evaluated:

\section{(1) More Effective Email Campaign}

Email campaigns used to need two to three days before execution. But with AI platform, it is possible to complete the preparation within a couple of hours (Reed, 2017).

\section{(2) Increase in Revenue}

AI-driven digital marketing efforts have increased the onsite revenue by $8 \%$ and the overall revenue by $4.2 \%$ (Reed, 2017). This is being achieved by adding features such as recommender and reminder systems to the AI platform (Tjepkema, 2017).

(3) Revealing the Truth

The company came to know the percentage of inactive customers. Such information provided to the company made it possible to convert the inactive into active customers. If the customers are no more there or no more interested, their accounts will be deleted from the database (Reed, 2017).

(4) Customer Profiling

Emarsys AI platform is helping FreeStyleXtreme to build individual customer profiles based on their preferences and previous online experience with Omni channels (Tjepkema, 2017). This will in turn increase the customer experience.

(5) Personalization

With the Emarsys AI platform, the company can personalize all communication with customers, including bespoke emails in their own language and ensuring that the viewed homepage presents the goods they are 
most likely to buy (Tjepkema, 2017).

\section{(6) Reduction in Manpower Requirement:}

According to the CEO of the company, the company would need $200 \sim 300 \%$ without the above-mentioned AI-based systems (Administrator, 2018).

\section{Cross-channel Performance Advertising Platform - Marin Software}

The marin software is the cross-channel performance advertising platform which consists of patented bidding algorithm (https://www.marinsoftware.com/resources/case-studies/freestylextreme-increaserevenue). According to Franklin (2017), FreeStyleXtreme made use of Google AdWords with great success in Ireland and the UK, and the company was able to acquire new customers. However, FreeStyleXtreme observed that its Cost per Acquisitions (CPAs) was increasing. As a part of its strategy, FreeStyleXtreme rebuilt their Google AdWords accounts and exacted matching strategies via 17 accounts with 120 campaigns, 25,000 ad groups, and up to 800,000 keywords per account. But it was discovered that three reasons have limited its success:

(i) Only one person was allowed for maintaining the account;

(ii) It was impossible to manage bids manually with very high volume of keywords in different languages;

(iii) There is limitation in expanding campaigns across new publishers and online advertising channels due to resource constraints.

To overcome these shortcomings, the company implemented Marin software, which used a patented bidding algorithm. This has resulted in many benefits such as $69 \%$ increase in revenue, $110 \%$ increase in conversion rate, $57 \%$ decrease in CPA, and $28 \%$ decrease in spending.

\section{Carrier management - Route Genie software}

Route Genie software is the successor of iForce Pathfinder, which helps the company to conduct service to retailers and the end consumer. FreeStyleXtreme replaced its carrier management system with Route Genie, which is believed to be best in order fulfillment and returns segment in UK for a three-year period initially. It has a unique feature of innovative addressing solutions, offers efficient reporting features and superior services, and integrates itself with the leading domestic and international carriers. The objectives of the replacement of the carrier management system are as follows:

(a) To handle overseas orders (approximately $70 \%$ of total orders);

(b) Efficiently managing carriers with reduced cost;

(c) To provide diverting traffic if carriers have service issues;

(d) To use multiple carriers to deal with the peak seasons and extraordinary circumstances;

(e) To customize messages delivered at chosen trigger points along the delivery process for home delivery and Click \& Collect. 
Route Genie has enhanced consistency and the overall brand experience (News, 2016; Briggs, 2018).

In addition, Route Genie data help in determining the total profit and loss made by all shipments across the business, which is especially useful for the case when items are being sent overseas. The statistics can be available from Route Genie and fed into the retailer's dedicated 'Profit and Loss Dashboard' within its CRM system in just 24 hours. This allows FreestyleXtreme to have greater transparency in service costs and problems with product pricing (News, 2016; Briggs, 2018). In all, Marin software is more in the transformation category in comparison to the informate and automate categories of the systems as suggested by Schein (1992) and Zuboff (1988).

\section{Cloud-based Warehouse Management System from Snapfulfil}

Strzalek (2017) reported that the company implemented Snapfulfil (https://www.snapfulfil.com/), the cloud-based Warehouse Management System (WMS), in order to drive efficiency in its global fulfilment operation. He mentioned that its warehouse management module of the ERP system lacked both the functionality and flexibility the company need to handle purchases of 30,000 SKUs and 100,000 items, which are sold via 20 international websites to 60 countries (Tran, 2017). This is the reason for the adoption of the new system. The new cloud-based WMS brought about benefits to the company. As reported by Strzalek (2017), the company is handling 800 more orders daily and 108\% more in total transaction volume with only three additional staff, working an eight-hour shift rather than twelve. This figure can be more than double in the run up to the peak (Morrell, 2017). The company has also reduced the sending errors from $0.4 \%$ to $0.06 \%$ (Source: file://C:/Users/hp/Downloads/freestylextreme-full-uk.pdf). Anton (2017) remarked that the company has harvested four benefits through its implementation of the cloud-based WMS - connectivity, intelligence, capability and speed. This software is more in the transformation category for warehouse management followed by the automate and informate categories as suggested by Schein (1992) and Zuboff (1988).

\section{New Order Processing System,}

The first implemented order processing system of FreeStyleXtreme was hampering the growth of the company due to a lack of efficiency in operation. The company then solved the problem of back-end processes by introducing a new system. This system, along with the new stock control system, is directly responsible for the company's spectacular progress in 2011 - increased profitability, operation process and fans' retention (The Marketing Society, 2013). The addition of a new screen in the order-processing system was utilized for the quick identification of the orders that were running low on stock, and those orders fulfilled by the warehouse.

The system had reduced the number of clicks needed to process the orders, not only speeding up the process but reducing mistakes through the simplification of the process. It has streamlined the workflow by separating the completed and ready-to-be-sent orders from others that are still in progress with the various marketing channels. Additional features of this system include the follows: 
(i) An allocation module that ensures that packing stations receive what needs to be packed in terms of products and quantity;

(ii) A currency conversion tool on the order basis so that sales reports in pound sterling take account of the variations in the exchange rate;

(iii) Assignment of the cost price for booking in stock batches, and direct banking payment for Germany, helping the company to globalize its business (The Marketing Society, 2013).

The new system has sorting and filtering options for the product lists, which help in updating the product details quickly. Such changes make it possible to process a higher volume of orders more efficiently. It resulted in a cutting of the running costs by $£ 60,000$ per year (a whopping $10 \%$ of the operation costs), as well as a $100 \%$ business growth without laying off any loyal staff. The new system has also improved the customer lifetime value by $20 \%$ as orders are dispatched faster and fewer customers find that their desired items are out of stock (The Marketing Society, 2013).

\section{New Stock Control System,}

The new automated stock-control system is much faster and easier to use than before. With its implementation, the out-of-stock items would no longer appear on the website. The back-office staff do not have to spend their time removing these items manually from the product list on the website. This has eliminated disappointing communications between the customer service staff and the customers in the case that their choice was unavailable. Besides, this has also reduced the time needed for processing refunds. The system allows the cost price to be assigned at the 'batch of stock' level, which delivers more accurate profit and loss calculations (The Marketing Society, 2013).

\section{ERP and CRM System Implemented along with the E-commerce Website.}

FreeStyleXtreme does not mention directly about the ERP and CRM systems. However, while justifying the implementation of the new systems, it is reported that the existing ERP or CRM systems were not in line with the growth of the company and could not handle business efficiently. Therefore, these systems have

been augmented with new systems to deal with the large number or purchase. It could be a new version of the existing systems or the company might have added more user licenses.

\section{SAGE 200 Accounting System}

It is reported in a case study that FreeStyleXtreme is using SAGE 200 accounting system and the bespoke CMS, an in-house developed System. Croud (2018) reported that FreeStyleXtreme has developed proprietary systems, and the new cloud-based WMS system from Snapfulfil needs to be integrated with these two systems. FreeStyleXtreme is customizing the adopted systems in-house to better meet its business requirements. 
Table 7 Recent Statistics of FreeStyleXtreme Website

\begin{tabular}{|l|l|l|l|l|l|}
\hline Date & Bounce Rate & $\begin{array}{l}\text { Daily Page } \\
\text { views per } \\
\text { Visitor }\end{array}$ & $\begin{array}{l}\text { Daily Time } \\
\text { on Site }\end{array}$ & $\begin{array}{l}\text { Alexa Global } \\
\text { Rank }\end{array}$ & $\begin{array}{l}\text { Alexa UK } \\
\text { Rank }\end{array}$ \\
\hline Oct.28, 2018 & $42.70 \%$ & 6.70 & 3.56 & 83,360 & 9,731 \\
\hline Jan. 24, 2019 & $40.40 \%$ & 7.00 & 4.09 & 74,404 & 10,278 \\
\hline June 22, 2019 & $45.50 \%$ & 4.50 & 3.15 & 94,530 & 24,964 \\
\hline August 11, 2019 & $49.20 \%$ & 3.40 & 2.24 & 95,033 & 8,974 \\
\hline
\end{tabular}

Source:https://www.alexa.com/siteinfo/freestylextreme.com; http://freestylextreme.com.cutercounter.com/

Table 8 Facebook Data

\begin{tabular}{|l|l|l|l|l|l|}
\hline Year & $\begin{array}{l}\text { Facebook } \\
\text { Fans }\end{array}$ & $\begin{array}{l}\text { Sales } \\
\text { Conver- } \\
\text { sion }\end{array}$ & Revenue & $\begin{array}{l}\text { Unique Visits / } \\
\text { Visits }\end{array}$ & Source \\
\hline 2010 & 19,583 & 236 & $€ 22,117$ & $\begin{array}{l}1,610,386 \\
2,390,195\end{array}$ & The Marketing Society (2013) \\
\hline 2011 & 58,485 & 775 & $€ 57,729$ & $\begin{array}{l}2,465,754 / \\
4,064,485\end{array}$ & The Marketing Society (2013) \\
\hline 2013 & 100,000 & NA & NA & NA & Marotta (2013), \\
\hline 2016 & 240,000 & NA & NA & NA & Enterprise Nation (2016) \\
\hline 2019 & 620,085 & NA & NA & NA & \\
\hline
\end{tabular}

Source:

https://wWw.owler.com/company/freestylextreme\#website-history\&Websiteofsocialmediaplatforms

\section{Social Media and FreeStyleXtreme}

FreeStyleXtreme had presence on popular social media sites such as Facebook, twitters, Instagram, and YouTube. The Company has been working with the experts of conversion to take full advantage of the various forms of social media (https://conversion-rate-experts.com/freestylextreme-testimonial/).

\section{Facebook}

The company had a small presence on Facebook during 2010. But its Facebook fan base has grown many times as the evidence given in Table $\mathbb{0}$ and Table $\mathbf{\nabla}$. The recent data given in Table $\mathbf{\nabla}$ indicates very good growth of its Facebook fans. The company is using technology to convert its fan base to customer base, but the customer base is on decline at Facebook. 
Table 9 Additional Social Media Data

\begin{tabular}{|l|l|l|l|l|}
\hline Date & Facebook Likes & Twitter Followers & You Tube Views & Instagram Followers \\
\hline Aug. 1, 2015 & $205 \mathrm{~K}$ & NA & NA & NA \\
\hline Nov. 1,2015 & $228 \mathrm{~K}$ & NA & NA & NA \\
\hline Feb. 1, 2016 & $277 \mathrm{~K}$ & NA & NA & NA \\
\hline Nov. 10, 2016 & $356 \mathrm{~K}$ & $11.1 \mathrm{~K}$ & $322 \mathrm{~K}$ & $15.5 \mathrm{~K}$ \\
\hline Feb. 16, 2017 & $420 \mathrm{~K}$ & $11.2 \mathrm{~K}$ & $328 \mathrm{~K}$ & $16.1 \mathrm{~K}$ \\
\hline June 1,2017 & $472 \mathrm{~K}$ & $11.2 \mathrm{~K}$ & $328 \mathrm{~K}$ & $16.6 \mathrm{~K}$ \\
\hline Sept. 21,2017 & $532 \mathrm{~K}$ & $11.3 \mathrm{~K}$ & $336 \mathrm{~K}$ & $17.4 \mathrm{~K}$ \\
\hline Oct. 8,2018 & $621 \mathrm{~K}$ & $10.8 \mathrm{~K}$ & $344 \mathrm{~K}$ & $19.2 \mathrm{~K}$ \\
\hline Feb. 23, 2019 & 619,664 & $10.7 \mathrm{~K}$ & 351,242 & $20.3 \mathrm{~K}$ \\
\hline March 12, 2019 & 620,092 & $10.7 \mathrm{~K}$ & 351,607 & $20.5 \mathrm{~K}$ \\
\hline Aug. 11, 2019 & 617,244 & $10.7 \mathrm{~K}$ & 354,805 & $20.9 \mathrm{~K}$ \\
\hline
\end{tabular}

Source:

https://wWw.owler.com/company/freestylextreme\#website-history;WebsitesofSocialMediaPlatforms

Table 10 Twitter Data

\begin{tabular}{|l|l|l|l|l|l|}
\hline Date & Tweets & Following & Follower & Likes & Video \& Photos \\
\hline Oct. 31, 2018 & 6,923 & 5,230 & $10.8 \mathrm{~K}$ & 1,276 & 1,496 \\
\hline Feb. 23, 2019 & 6,958 & 5,147 & $10.7 \mathrm{~K}$ & 1,279 & 1,524 \\
\hline March 12, 2019 & 6,965 & 5,131 & $10.7 \mathrm{~K}$ & 1,280 & 1,527 \\
\hline Aug. 11, 2019 & 6,993 & 5,082 & $10.7 \mathrm{~K}$ & 1,271 & 1,540 \\
\hline
\end{tabular}

Source: Twitter Page of FreeStyleXtreme

\section{Twitter}

FreeStyleXtreme joined twitter in May 2009. As per the data given in Tableسు, the number of twitter followers increased to $11.3 \mathrm{~K}$ during September 2017. It reduced to $10.8 \mathrm{~K}$ during October, 2018, which is not a desirable sign for the company. It reduced further to 10.7K on Feb. 23, 2019. Other statistics of the company on twitter are given as in Tableس. It indicates that the activities in terms of following, followers, likes, and video \& photos reached the saturation level.

\section{YouTube}

FreeStyleXtreme joined YouTube on May 19, 2006. Part of the YouTube data is presented as in Tableس. On Nov. 10, 2018, the number of YouTube views stands as 349,074 and there are 912 subscribers. These figures increased to 351,242 views and 934 subscribers on Feb. 23, 2019. 
Table 11 YouTube Data

\begin{tabular}{|l|l|l|}
\hline Date & Views & Subscribers \\
\hline Nov. 10, 2018 & 349,074 & 912 \\
\hline Feb. 23, 2019 & 351,242 & 934 \\
\hline March 12, 2019 & 351,607 & 937 \\
\hline Aug. 11, 2019 & 354,805 & 965 \\
\hline
\end{tabular}

Source: YouTube Page of FreeStyleXtreme

Table 12 Instagram Data

\begin{tabular}{|l|l|l|l|}
\hline Date & Followers & Following & Posts \\
\hline Dec. 1,2018 & $19.8 \mathrm{~K}$ & 2451 & 922 \\
\hline Jan. 21, 2019 & $20.1 \mathrm{~K}$ & 2477 & 938 \\
\hline Feb. 23, 2019 & $20.3 \mathrm{~K}$ & 2442 & 947 \\
\hline March 12, 2019 & $20.5 \mathrm{~K}$ & 2440 & 951 \\
\hline Aug. 11, 2019 & $20.9 \mathrm{~K}$ & 2,428 & 963 \\
\hline
\end{tabular}

Source: FreeStyleXtreme webpage

\section{Instagram}

Part of the Instagram data about FreeStyleXtreme is presented in Tableए2. Its followers have been growing at a high rate. In December, 2018, it has $19.8 \mathrm{~K}$ followers, 2451 following, 1745 tags, and 922 posts. On January 21, 2019, it has 20.1K followers, 2447 following, and 938 posts.

\section{Conclusion Remarks}

From the data above, we can see that the information systems / technologies implemented by FreeStyleXtreme help the company to realize more effective business processes as a retailer, including its order tracking, order fulfilment, managing warehouses and advertisement. The new systems have also improved the productivity of the employees and the supply chain. As a result, the company has increased considerably over the decade in terms of sales and geographical reach with a much lower employment expansion ratio. The cloud - based WMS information systems have converted its supply chain into a most efficient system for distribution of goods.

It is evident that the adoption of information systems / technologies is driven by both internal and external factors. Information systems / technologies are implemented as per the need and availability in the market. FreeStyleXtreme has integrated various systems for product management, service, online shopping, ERP and other technologies and customized to meet its own need in productivity enhancement ( $\mathrm{Su}$ and $\mathrm{Fu}, 2015$ ).

FreeStyleXtreme is disrupting the sports clothing industry with a unique approach to customer experience. 
Its core strategy is customer satisfaction. To achieve this goal, it is implementing information systems /technologies and adding new features into its existing information systems. It works on the principles of enhancing customer satisfaction, increasing productivity without layoffs. Efficient utilization of warehouses, reduction in loss and operations helped the company achieve further growth. As the same time, it makes the optimal use of its presence in social media but to a limited extent. It has replaced legacy information systems with new information systems having better features to meet the business requirement on a regular basis. Its implementation of AI based systems is a unique example for a company of its size. Having a small number of employees, the company requires a smaller number of user licenses, thereby less cost for operation.

In conclusion, the journey of the company started with its presence of an e-commerce website that has implemented artificial-intelligence(AI)-based systems to run its business.

\section{References}

Administrator, 2018. Artificial Intelligence Hype. Retrieved on September 12, 2018 from https:// musatotech.co.za/artificial-intelligence-hype/.

Anton, C., 2017. What Cloud Computing and SaaS WMS Can Do for Your Warehouse. Retrieved on November 11, 2018 from https://blog.snapfulfil.com/what-cloud-computing-and-saas-wms-can-do-foryour-warehouse.

Baker, H., 2018. This Bristol Sports Company Moving to Europe over Brexit and Is Warning May Axe Jobs. Retrieved on January 21, 2019 from https://www.bristolpost.co.uk/news/business/bristolsports-company-moving-europe-2343320.

Briggs, F., 2017. Action Sports Retailer FreestyleXtreme Uses AI to Boost Web Revenues by 8\%. Retrieved on October 23, 2018 from https://www.retailtimes.co.uk/action-sports-retailerFreestyleXtreme-uses-ai-boost-web-revenues-8/.

Briggs, F., 2018. Locpin's Precise Addressing Solution to Be Added to Route Genie Platform. Retrieved on October 31, 2018 from https://www.retailtimes.co.uk/locpins-precise-addressing-solutionto-be-added-to-route-genie-platform/.

B2C Europe, 2019. How FreestleXtreme Saved Thousands of Euros with B2C. Retrieved on Dec. 1, 2019 from https://www.b2ceurope.eu/new/freestylextreme-saved-thousands-euros-b2c//.

Croud, 2018. Going Global: The UK SMEs Making Exporting Look Easy. Retrieved on January 24, 2019 from https://insight.croud.com/hubfs/.../Croud\%20Going\%20Global\%20Report\%202018.p.

Dawson, C., 2018. Meet The Company: Wndirect. Retrieved on October 31, 2018 from https://tamebay. com/2018/02/meet-company-wndirect.html.

Enterprise Nation, 2016. Go Global: How Freestyle Extreme Did Business in Ireland. Retrieved on September 12, 2018 from https://www.enterprisenation.com/blog/go-global-how-freestyle-extremedid-business-in-ireland/.

Everett, C., 2017. Is Artificial Intelligence Hype Sowing Damaging Confusion? Retrieved on January 24, 2019 from https://wWw.computerweekly.com/feature/Is-artificial-intelligence- 
hype-sowing-damaging-confusion.

Franklin, 1., 2017. Seller Spotlight: How FreestyleXtreme Gets Over 800 Positive Reviews Every Month. Retrieved on September 28, 2018 from https://www.xsellco.com/resources/FreestyleXtreme-amazonebay-reviews/.

LogisticManager.com, 2016. Sports Retailer Switches Carrier Management System. Retrieved on Sept. 30, 2019. https://www.logisticsmanager.com/sports-retailer-switches-carrier-managementsystem/.

Marin Software, 2019. FreestyleXtreme.com Revenue Jumps Up 69\% with Marin Software. Retrieved on Dec. 7, 2019 from https://www.marinsoftware.com/resources/case-studies/freestylextremeincrease-revenue.

Marotta, D., 2013. FreestyleXtreme, June 04. Retrieved on September 14, 2018 from https: //translate.google.com/translate?hl=en\&sl=it\&u=https://www.dorafashionspace.com/ FreestyleXtreme/\&prev=search

Media Release, 2017. FreestyleXtreme Chooses Emarsys AI-Enabled Marketing Platform to Support International Growth Plans, June 22. Retrieved on September 05, 2018 from https://www.computerworld. com.au/mediareleases/30343/FreestyleXtreme-chooses-emarsys-ai-enabled/.

Morrell, L., 2017. FreestyleXtreme Supports Rapid Growth with Launch of New WMS from Snapfulfil. Retrieved on September 05, 2018 from https://edelivery.net/2017/07/FreestyleXtreme-supportsrapid-growth-launch-new-wms-snapfulfil/

News, 2016. IForces Route Genie to Drive Efficient Carrier Management for FreestyleXtreme, June 18. Retrieved on Sept. 30, 2019 from https://www.financedigest.com/iforces-route-genie-to-driveefficient-carrier-management-tor-Freestylextreme.ntmı.

News, 2016. Route Genie Teams Up with Asda's Parcel Toyou Service. Retrieved on March 31, 2019 from http://www.analytiqa.com/news/latest-supply-chain-developments/route-genie-teamsup-with-asdas-parcel-toyou-service

Reed, D., 2017. FreestyleXtreme Sales Climb 8\% with AI Leg Up. Retrieved on September 05, 2018 from https://www.dataiq.co.uk/article/FreestyleXtreme-sales-climb-8-ai-leg.

Schein, E. H., 1992. "The Role of The CEO in The Management of Change: The Case of Information Technology", in Kochan, T.A. and Useem, M. (Eds), Transforming Organizations, Oxford University Press, Oxford. Retrieved on Sept. 30, 2019 from https://dspace.mit.edu/bitstream/handle/1721. 1/2271/SWP-3072-21290235.pdf?sequence=1\&isAllowed=y

Snapfulfil, 2017. Extreme Sports Retailer Conquers Warehousing Challenges with Snapfulfil. Retrieved on January 21, 2019 from https://sctimes.io/news/article.aspx?tid=35\&aid=4396.

Strzalek, A., 2017. FreestyleXtreme Boosts Warehouse Management, July 26. Retrieved on September 10, 2018 from http://www.retail-systems.com/rs/Freestyle_Xtreme_Warehouse_Management.php

The Marketing Society, 2013. 2012: FreestyleXtreme, Process to Profit - Case study, May 01. Retrieved on September 20, 2018 from https://www.marketingsociety.com/the-library/2012FreestyleXtreme-process-profit-case-study\#AmJs81X2X1YkVUFr.97 
Tjepkema, J., 2017. FreestyleXtreme Chooses Emarsys AI-enabled Marketing Platform to Support International Growth, 21st June. Retrieved on September 05, 2018 from https://www.emarsys.com/en/ press-release/FreestyleXtreme-chooses-emarsys-ai-enabled-marketing-platform-supportinternational-growth-plans/

Tran, D., 2017. Freestyle Extreme Implements Snapfulfil's Warehouse Management system, August 03. Retrieved on September 15, 2018 from https://www.shdlogistics.com/news/freestyle-extremeimplements-snapfulfils-warehouse-management-system.

Warehouse and Logistics News UK, 2018. Snapfulfil Drives Dramatic Improvements for Action Sports Retailer. Retrieved on October 20, 2018 from http://ichainnel.com/en/news/1029317_ciecnqsnapfulfil-drives-dramatic-improvements-for-action-sports-retailer/

Zuboff, S., 1988. In the Age of Smart Machine: The Future of Work and Power. Basic Books, New York, NY. 